\title{
Components of near-surface energy balance derived from satellite soundings - Part 2: Noontime latent heat flux
}

\author{
K. Mallick ${ }^{1}$, A. Jarvis ${ }^{2}$, G. Wohlfahrt ${ }^{3,8}$, G. Kiely ${ }^{4}$, T. Hirano ${ }^{5}$, A. Miyata ${ }^{6}$, S. Yamamoto ${ }^{7}$, and L. Hoffmann ${ }^{1}$ \\ ${ }^{1}$ Environmental Research and Innovation (ERIN), Luxembourg Institute of Science and Technology (LIST), L4422, Belvaux, \\ Luxembourg \\ ${ }^{2}$ Lancaster Environment Centre, Lancaster University, Lancaster LA1 4YQ, UK \\ ${ }^{3}$ Institute of Ecology, University of Innsbruck, 6020 Innsbruck, Austria \\ ${ }^{4}$ Hydrology Micrometeorology and Climate Investigation Centre, Department of Civil and Environmental Engineering, \\ University College Cork, Cork, Ireland \\ ${ }^{5}$ Division of Environmental Resources, Research Faculty of Agriculture, Hokkaido University, Hokkaido, Japan \\ ${ }^{6}$ National Institute for Agro-Environmental Sciences, Tsukuba, Japan \\ ${ }^{7}$ Graduate School of Environmental Science, Okayama University Tsushimanaka 3-1-1, Okayama 700-8530, Japan \\ ${ }^{8}$ European Academy of Bolzano, 39100, Bolzano, Italy
}

Correspondence to: K. Mallick (kaniska.mallick@gmail.com)

Received: 27 March 2014 - Published in Biogeosciences Discuss.: 4 June 2014

Revised: 31 October 2014 - Accepted: 10 November 2014 - Published: 22 December 2014

\begin{abstract}
This paper introduces a relatively simple method for recovering global fields of latent heat flux. The method focuses on specifying Bowen ratio estimates through exploiting air temperature and vapour pressure measurements obtained from infrared soundings of the AIRS (Atmospheric Infrared Sounder) sensor onboard NASA's Aqua platform. Through combining these Bowen ratio retrievals with satellite surface net available energy data, we have specified estimates of global noontime surface latent heat flux at the $1^{\circ} \times 1^{\circ}$ scale. These estimates were provisionally evaluated against data from 30 terrestrial tower flux sites covering a broad spectrum of biomes. Taking monthly average 13:30 data for 2003, this revealed promising agreement between the satellite and tower measurements of latent heat flux, with a pooled root-mean-square deviation of $79 \mathrm{~W} \mathrm{~m}^{-2}$, and no significant bias. However, this success partly arose as a product of the underspecification of the AIRS Bowen ratio compensating for the underspecification of the AIRS net available energy, suggesting further refinement of the approach is required. The error analysis suggested that the landscape level variability in enhanced vegetation index (EVI) and land surface temperature contributed significantly to the statistical metric of the predicted latent heat fluxes.
\end{abstract}

\section{Introduction}

The spectre of increasing global surface temperatures means our ability to both monitor and predict changes in the activity of the water cycle becomes critical if we are to develop the adaptive capability needed to manage the effects of this change (Lawford et al., 2004). As a result, significant investments have been and are being made in developing both monitoring and modelling capacity in the related areas of water resource management (Nickel et al., 2005), flood and drought risk assessment (Lehner et al., 2006), and weather and climate prediction (Irannejad et al., 2003; Brennan and Lackmann, 2005). Of the various components of the water cycle, the accuracy with which evaporative fluxes, $E$ (or latent heat fluxes, $\lambda E$ ), are both measured and hence modelled at scales relevant to decision making has been identified as an area where greater capacity is needed, particularly in order to evaluate and hence better constrain model performance (Chen and Dudhia, 2001; McCabe et al., 2008). These scales range from 1 to $100 \mathrm{~km}$ (i.e. 0.01 to $1^{\circ}$ ) in the spatial extent.

Satellites offer a potentially attractive source of data for calculating $E$ at scales directly relevant to model development (from 0.01 to $1^{\circ}$; Jiminez et al., 2009). Over the past 30 years a variety of schemes for specifying $E$ using remote 
sensing data have been developed and used to evaluate the spatio-temporal behaviour of evaporation for field (Tasumi et al., 2005), regional (Bastiaanssen et al., 1998; Su, 2002; Mu et al., 2007; Mallick et al., 2007; Jang et al., 2010) and continental scales (Anderson et al., 2007; Sahoo et al., 2011). The methods employed thus far can be categorised based on the various approaches followed to determine $E$. The most common approach centres on assuming a physical model of evaporation given many of the variables required to compute evaporation using these models are available directly as satellite products (e.g. land surface temperature, vegetation index, albedo) (Choudhury and Di Girolamo, 1998; Mu et al., 2007, 2011). The Priestley-Taylor (Priestley and Taylor, 1972)-based model for estimating monthly global $E$ relies on constraining the Priestley-Taylor parameter with meteorological and satellite-based biophysical variables (fractional vegetation cover, green canopy fraction, vegetation index, etc.) (Fisher et al., 2008; Vinukollu et al., 2011). In contrast, a number of studies have also tried to resolve $E$ indirectly by estimating the evaporative fraction from the relationship between satellite-derived albedo, vegetation indices and land surface temperature (Verstraeten et al., 2005; Batra et al., 2006; Mallick et al., 2009). More recently, Salvucci and Gentine (2013) proposed a novel method for determining $E$ based on minimising the vertical variance of relative humidity while simultaneously estimating water vapour conductance and $E$. A list of the widely used global- and regional-scale satellite-based $E$ models is listed in Table 1.

What is common to all these approaches is that they rely to a greater or lesser extent on parameterisation of surface characteristics in order to derive the estimates of $E$ and therefore the products from these approaches are conditional on these parameterisations. For example, in schemes which exploit the Penman-Monteith equation, both the aerodynamic and surface resistance terms require some form of calibration of surface characteristics, often involving vegetation indices, whether empirically (Mu et al., 2007) or through linking to photosynthesis (Anderson et al., 2008). This is obviously a confounding factor when one attempts to use these data to evaluate surface parameterisations in weather, climate and hydrological models, particularly when the models we wish to evaluate may contain very similar model descriptions for $E$. What is required, therefore, are methods for deriving $E$ estimates from satellite data that do not rely unduly on surface parameterisations, and thus they become a valid and valuable data source for model evaluation. One approach that appears to fulfil this requirement is where $\lambda E$ is estimated from satellite data as a residual term in the energy balance equation (Tasumi et al., 2005; Mallick et al., 2007). However, this approach suffers from the effects of error propagation because all errors, including any lack of observed closure of the regional energy budget, are lumped into the estimate of $\lambda E$ (Foken et al., 2006). From this we can see that something more akin to a satellite "observation" would be attractive.
Global polar-orbiting sounders like AIRS (Atmospheric Infrared Sounder) provide profiles of air temperature and relative humidity at different pressure levels from the surface to the upper troposphere, along with several other geophysical variables (for example, surface temperature, near-surface air temperature, precipitable water, cloudiness, surface emissivity, geopotential height). Profile information like this points to the possibility of exploring gradient-based methods such as Bowen ratio (Bowen, 1926) to produce large-scale estimates of $E$. Despite having been used to refine estimate of near-surface air temperature over the oceans (e.g. Hsu, 1998), the use of Bowen ratio methods in conjunction with satellite sounder data somewhat surprisingly appears to have been overlooked as a method for estimating $E$. The reasons for this are probably twofold. Firstly, the resolutions of the temperature and humidity retrievals are assumed to be inadequate for differential methods like this. Secondly, there can be reservations over the applicability of the underlying assumptions of gradient methods on this scale. Although these appear valid concerns, there are also important counter-arguments to consider. Firstly, the degree of signal integration going on at the scale of the satellite sounding should help relax the requirement on signal resolution. Sounders integrate signal horizontally over scales of thousands of square kilometres and hence benefit from strong spatial averaging characteristics in the measurement, despite suffering from ambiguities in the vertical integration of signal. However, this later drawback is aided by an effectively large sensor separation in the vertical (Thompson and Hou, 1990). Secondly, studies over both ocean and land indicate that the Bowen ratio method can be relatively robust under non-ideal conditions (Tanner, 1961; Todd et al., 2000; Konda, 2004). Given the potential benefits of having non-parametric estimates of $E$ at the scales and spatial coverage offered by the satellites, we argue that the possibility of using sounder products within a Bowen ratio framework merits investigation.

This paper presents the development and evaluation of $1^{\circ} \times 1^{\circ}$ AIRS sounder-Bowen ratio-derived latent heat flux, $\lambda E$. We focus on terrestrial systems because of the availability of an extensive tower-based flux measurement network against which we can evaluate the various satellite-derived components.

\section{Methodology}

\subsection{Bowen ratio methodology}

The Bowen ratio $(\beta)$ is the ratio of sensible, $H\left(\mathrm{~W} \mathrm{~m}^{-2}\right)$, to latent, $\lambda E\left(\mathrm{~W} \mathrm{~m}^{-2}\right)$, heat flux (Bowen, 1926),

$\beta=\frac{H}{\lambda E}$,

where $\lambda$ is the latent heat of vaporisation of water $\left(\mathrm{J} \mathrm{kg}^{-1}\right)$ and surface to atmosphere fluxes are positive. If the instan- 
Table 1. A list of satellite-based evapotranspiration models.

\begin{tabular}{|c|c|c|c|}
\hline Model name & Modelling approach & Input variables & Reference \\
\hline ALEXI/TSEB & Two-source aerodynamic model & $R_{\mathrm{N}}, G, T_{\mathrm{S}}, W_{\mathrm{S}}, L_{\mathrm{AI}}, f_{\mathrm{C}}$ & $\begin{array}{l}\text { Anderson et al. (2007), } \\
\text { Norman et al. (1995) }\end{array}$ \\
\hline SEBS & Single-source aerodynamic model & $R_{\mathrm{N}}, G, T_{\mathrm{S}}, T_{\mathrm{A}}, W_{\mathrm{S}}, L_{\mathrm{AI}}, f_{\mathrm{C}}$ & $\mathrm{Su}(2002)$ \\
\hline SEBAL & Single-source aerodynamic model & $R_{\mathrm{N}}, G, T_{\mathrm{S}}, T_{\mathrm{A}}, W_{\mathrm{S}}, L_{\mathrm{AI}}, f_{\mathrm{C}}$ & Bastiaanssen et al. (1998) \\
\hline METRIC & Single-source aerodynamic model & $R_{\mathrm{N}}, G, T_{\mathrm{S}}, T_{\mathrm{A}}, W_{\mathrm{S}}, L_{\mathrm{AI}}, f_{\mathrm{C}}$ & Tasumi et al. (2005) \\
\hline RH variance & Single-source Penman-Monteith model & $R_{\mathrm{N}}, G, R_{\mathrm{H}}, T_{\mathrm{A}}, W_{\mathrm{S}}$ & Salvucci and Gentine (2013) \\
\hline PM-MOD16 & Three-source Penman-Monteith model & $R_{\mathrm{N}}, G, R_{\mathrm{H}}, T_{\mathrm{A}}, L_{\mathrm{AI}}, f_{\mathrm{C}}$ & Mu et al. (2007) \\
\hline PTJPL & Three-source Priestley-Taylor model & $R_{\mathrm{N}}, G, R_{\mathrm{H}}, T_{\mathrm{A}}, L_{\mathrm{AI}}, f_{\mathrm{C}}$ & Fisher et al. (2008) \\
\hline $\mathrm{EF}_{\mathrm{VI}-\mathrm{T}_{\mathrm{S}}}$ & Two-dimensional scatter between $T_{\mathrm{S}}$ and VI & $R_{\mathrm{N}}, G, T_{\mathrm{S}}, T_{\mathrm{A}}, \mathrm{VI}$ & Batra et al. (2006) \\
\hline $\mathrm{EF}_{\mathrm{alb}}-\mathrm{T}_{\mathrm{S}}$ & Two-dimensional scatter between $T_{\mathrm{S}}$ and albedo & $R_{\mathrm{N}}, G, T_{\mathrm{S}}, T_{\mathrm{A}}$, albedo & Verstraeten et al. (2005) \\
\hline
\end{tabular}

$R_{\mathrm{N}}$ : net radiation; $G$ : ground heat flux; $T_{\mathrm{S}}$ : land surface temperature; VI: vegetation index; $L_{\mathrm{AI}}$ : leaf area index; $f_{\mathrm{C}}$ : fractional vegetation cover; $T_{\mathrm{A}}$ : air temperature; $R_{\mathrm{H}}$ : relative humidity; $W_{\mathrm{S}}$ : wind speed.

taneous energy balance of the plane across which $H$ and $\lambda E$ are being considered is given by

$\Phi=R_{\mathrm{N}}-G=\lambda E+H$,

where $\Phi\left(\mathrm{W} \mathrm{m}^{-2}\right)$ is known as the net available energy, $R_{\mathrm{N}}$ $\left(\mathrm{W} \mathrm{m}^{-2}\right)$ is the net radiation across that plane and $G\left(\mathrm{~W} \mathrm{~m}^{-2}\right)$ is the rate of system heat accumulation below that plane; then, combining Eqs. (1) and (2), one gets

$\lambda E=\frac{\Phi}{1+\beta}$.

Therefore, if $\Phi$ and $\beta$ are available, $\lambda E$ can be computed (Dyer, 1974). The estimation of $\Phi$ from satellite data is covered in a companion paper (Mallick et al., 2014). $\beta$ was estimated as follows.

$H$ and $\lambda E$ are assumed to be linearly related to the vertical gradients in air temperature and partial pressure of water vapour, $\partial T / \partial z$ and $\partial p / \partial z$, through assuming similarity in the pathways for the two fluxes.

$\lambda E=\rho \lambda \varepsilon k_{\mathrm{E}} \frac{\partial p}{\partial z}$

and

$H=\rho c_{\mathrm{P}} k_{\mathrm{H}} \frac{\partial T}{\partial z}$,

where $\varepsilon$ is the ratio of the molecular weight of water vapour to that of dry air, $\rho$ is air density $\left(\mathrm{kg} \mathrm{m}^{-3}\right), c_{\mathrm{p}}$ is air specific heat $\left(\mathrm{J} \mathrm{kg}^{-1} \mathrm{~K}^{-1}\right)$, and $k_{\mathrm{E}}$ and $k_{\mathrm{H}}$ are the effective transfer coefficients for water vapour and heat, respectively $\left(\mathrm{m} \mathrm{s}^{-1}\right)$ (Fritschen and Fritschen, 2005). If heat and water vapour occupy the same transfer pathway and mechanism through a plane, then $k_{\mathrm{E}} \approx k_{\mathrm{H}}$ (Verma et al., 1978) and Eqs. (1) and (4) reduce to

$\beta=\frac{c_{\mathrm{P}}}{\lambda \varepsilon} \frac{\partial T}{\partial p}$, suggesting $\beta$ can be estimated from the relative vertical gradient in $T$ and $p$ (Bowen, 1926). In the turbulent region of the atmosphere, eddy diffusivities for all the conserved scalars are generally assumed equal because they are carried by the same eddies and, therefore, are associated at source (Swinbank and Dyer, 1967). There is evidence to suggest $k_{\mathrm{H}}$ is greater than $k_{\mathrm{E}}$ under stable (early morning and late afternoon) conditions when heat gets transferred more efficiently than the water vapour (Katul et al., 1995) and when the effects of lateral advection of heat are significant (Verma et al., 1978). For non-neutral atmospheric conditions the turbulent efficiency for transporting water vapour is more than that for heat (Katul et al., 1995), and under such conditions $k_{\mathrm{E}}$ is greater than $k_{\mathrm{H}}$. For the near-convective conditions (early to mid-afternoon) the ratio of $k_{\mathrm{H}}$ to $k_{\mathrm{E}}$ is unity (Katul et al., 1995).

AIRS soundings for $T$ and $p$ are available for a range of pressure levels in the atmosphere (Tobin et al., 2006). Assuming the lowest available two pressure levels $p_{1,2}$ occur within a region of the planetary boundary layer within which Eqs. (4a) and (b) hold, then a finite difference approximation of Eq. (5) gives

$\beta=\frac{c_{\mathrm{P}}}{\lambda \varepsilon} \frac{\left(T_{1}-T_{2}+\Gamma\right)}{\left(p_{1}-p_{2}\right)}$,

where $\Gamma$ accounts for the adiabatic lapse rate in $T$, which in this case will be significant. Here we specify $\Gamma$ following Eq. (6.15) in Salby (1996), which when rearranged gives

$\Gamma=\frac{\ln \left(T_{2} / T_{1}\right) \Gamma_{\mathrm{d}}}{\ln \left(p_{2} / p_{1}\right) \kappa}$,

where $\Gamma_{\mathrm{d}}$ is the dry adiabatic lapse rate $\left(\sim 9.8 \mathrm{~K} \mathrm{~km}^{-1}\right)$ and $\kappa$ is the ratio of the specific gas constant $\left(\mathrm{J} \mathrm{kg}^{-1} \mathrm{~K}^{-1}\right)$ to the isobaric specific heat capacity $\left(\mathrm{J} \mathrm{kg}^{-1} \mathrm{~K}^{-1}\right)$.

There are typically three dominant assumptions affecting the applicability of Bowen ratio methods, and the validity of these is important in the present context. The first is that the 
observations of the vertical gradients are dominated by vertical transport, and hence the effects of advective fluxes are minimal. This is a real problem in traditional, small-scale, near-surface applications because the length of the vertical flux path being sampled is similar to that of many of the turbulent fluxes involved in near-surface heat and mass exchange. As a result, the observed vertical gradient can become partially distorted by the lateral advection of heat and water vapour (Wilson et al., 2001). In contrast, the satellite sounding data sample a radically different space with a horizontal extent varying from 0.5 to $1^{\circ}$. In this preliminary investigation we have opted to use the AIRS sounding data where the horizontal footprint is $1^{\circ} \times 1^{\circ}$ (or approximately $100 \mathrm{~km} \times 100 \mathrm{~km}$ ). For the vertical profile we exploit the 1000 and $925 \mathrm{mb}$ pressure level soundings, corresponding to heights of approximately 10 and $500 \mathrm{~m}$. Therefore the vertical scale is nearly 3.5 orders of magnitude smaller than the horizontal. Although advective fluxes occur across a range of scales in space, they are slow relative to the vertical exchange on these scales and hence should tend to distort the vertical gradient to a lesser extent than traditional Bowen towers.

The second assumption is related to the first in that the lateral advective fluxes become particularly important when the underlying land surface is heterogeneous because lateral import of heat or mass into the observation space from adjacent land patches will again distort the gradient measurements. For the reasons expressed above on the relative scales of the vertical and horizontal footprint of the sounding observations, such "edge effects" should be diminished, although it is important to appreciate that the landscape heterogeneity is likely to increase with scale. Therefore, although the satellite-based method we are proposing shows promise as an observation platform, relating these observations to unique surface characteristics is likely to be problematic (despite an attempt being made (Fig. 6) to explain the retrieval errors in light of the vegetation biophysical heterogeneity).

The final assumption is that the land-atmosphere system is in some form of dynamic equilibrium so that the vertical gradients representing vertical fluxes and changes in storage are trivial. The soundings we utilise are for a 13:30 overpass time. Although not universally so, the turbulent boundary layer tends to be approaching its most mature by this time of day and the average depth of the turbulent boundary layer should extend well beyond the $925 \mathrm{mb}$ level (Fisch et al., 2004). Therefore, the steady-state assumption implicit in Bowen ratio methods (Fritschen and Simpson, 1989) is probably closest to being fulfilled. That said, the development of the turbulent boundary layer depends on the nature of the (radiative) forcing it is experiencing and there may be many circumstances when it is still evolving at the 13:30 overpass time. Although this has implications for the steady-state assumption, it probably has bigger implications for the assumption that the boundary layer has developed beyond the lowest two available soundings and hence can be considered fully turbulent.

Although the system we are sampling is not the constant flux region near the surface, in effect we have a surface source region (sampled by the $1000 \mathrm{mb}$ sounding) exchanging with a well-mixed volume (sampled by the $925 \mathrm{mb}$ sounding). The flux exchange between these two should be approximately linear and equivalent in the concentration differences between the two, providing we are near dynamic equilibrium (i.e. the turbulent boundary layer is not growing/contracting excessively) and that additional fluxes into and out of the boundary layer (including phase changes) are small relative to the surface sourced fluxes of heat and water vapour.

The principle difficulty as far as we can ascertain is the effect of phase changes associated with cloud formation, producing latent warming of the boundary layer whilst removing water vapour. Providing this happens above the $925 \mathrm{mb}$ sounding, we anticipate it being less of a problem, but if it happens below this level then clearly this is problematic. Of course, this also impacts on the estimation of the net available energy.

The reliability of the estimates of $\beta$ also depends on the accuracy and resolution of the measurements of the temperature and humidity gradients. The AIRS products are quoted as having resolutions and accuracies of $\pm 1 \mathrm{~K} \mathrm{~km}^{-1}$ for $T$ and $\pm 10 \% \mathrm{~km}^{-1}$ for $p$ (Aumann et al., 2003; Tobin et al., 2006). Given Bowen ratio studies are invariably applied to small sensor separations of the order of metres, and at the point scale, precisions of $\pm 0.01{ }^{\circ} \mathrm{C}$ for temperature and $\pm 0.01 \mathrm{kPa}$ for vapour pressure are required (Campbell Scientific, 2005), making the AIRS sensitivities appear untenable. However, as mentioned above, the effective sensor separation of the order of hundreds of metres allied to the sounding integrating at the $10000 \mathrm{~km}^{2}$ scale should help lift these restrictions. There are missing data segments in the AIRS sounder profiles, which are particularly prominent at high latitudes, where presumably it is difficult to profile the atmosphere reliably near the surface, and over the mountain belts, where the lower pressure levels are intercepted by the ground.

A general sensitivity-uncertainty analysis was carried out to assess the propagation of uncertainty through the calculation scheme onto the estimates of $\lambda E$ (see Mallick et al., 2014, for details).

\subsection{Satellite data sources}

The AIRS sounder is carried by NASA's Aqua satellite, which was launched into a Sun-synchronous low Earth orbit on 4 May 2002 as part of NASA's Earth Observing System (Tobin et al., 2006). It gives global, twice-daily coverage at 01:30-13:30 from an altitude of $705 \mathrm{~km}$. In the present study we have used AIRS level 3 standard monthly products from 2003 , with a spatial resolution of $1^{\circ} \times 1^{\circ}$. The monthly products are simply the arithmetic mean, weighted by counts, of 
the daily data of each grid box. The monthly merged products have been used here because the infrared retrievals are not cloud-proof and the monthly products gave decent spatial cover in light of missing cloudy-sky data. The data products were obtained in hierarchical data format (HDF4) with associated latitude-longitude projection from NASA's Mirador data holdings (http://mirador.gsfc.nasa.gov/). These data sets included all the meteorological variables required to realise Eqs. (6) and (7).

\subsection{Tower evaluation data}

The satellite estimates of $\beta, \lambda E$ and $H$ were evaluated against 2003 data from 30 terrestrial FLUXNET eddy covariance towers (Baldocchi et al., 2001) covering 7 different biome classes. These tower sites were selected to cover a range of hydro-meteorological environments in South America, North America, Europe, Asia, Oceania and Africa. A comprehensive list of the site characteristics and the site locations are given in a companion paper (Mallick et al., 2014), which describes the specification of the satellite net available energy used here.

Eddy covariance has largely replaced gradient-based methods like the Bowen ratio as the preferred method for tower measurements of terrestrial water vapour and sensible heat flux. Because eddy covariance is not a gradient method it is an attractive source of evaluation data. Sensible and latent heat flux measurements were used as reported in the FLUXNET data base; in other words no corrections for any lack in energy balance closure (Foken, 2008; Wohlfahrt et al., 2009) were applied. The spatial scale of the tower eddy covariance footprint is of the order of $\sim 1 \mathrm{~km}^{2}$ and is hence on a scale approximately 4 orders of magnitude smaller than the $10000 \mathrm{~km}^{2}$ satellite data, which obviously has implications in heterogeneous environments (see above). The most important implication for spatial heterogeneity in the present context is that, in addition to complicating comparison with tower data, relating these observations to unique surface characteristics is likely to be problematic.

\section{Results}

\subsection{Bowen ratio - evaporative fraction evaluation}

Figure 1a shows the global distribution of annual average, 13:30 h estimates for $\beta$ for the year 2003 derived using the sounder method. The missing data segments are due to two data rejection criteria, one of which is already mentioned in Sect. 2.1. We have additionally imposed our own data rejection for $\beta$ when there is reversal of the vertical vapour pressure gradient under high radiative load. This condition is often encountered in hot, arid settings when large-scale advection causes the assumptions behind Bowen ratio methodology to become invalid (Rider and Philip, 1960; Perez et al., 1999). This condition was particularly prevalent over

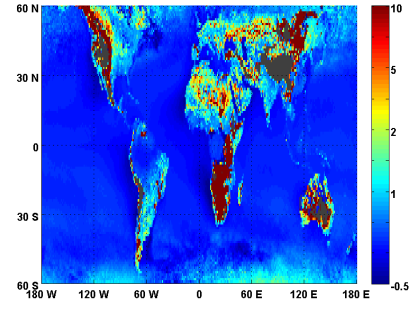

a.

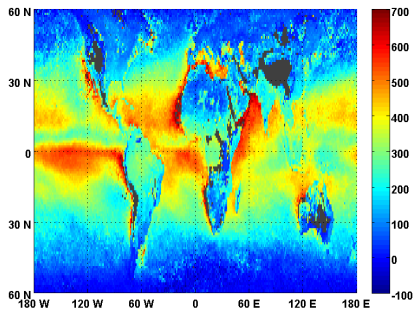

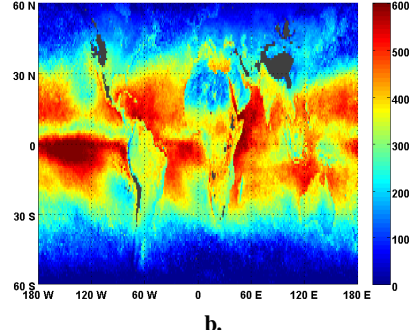

b.

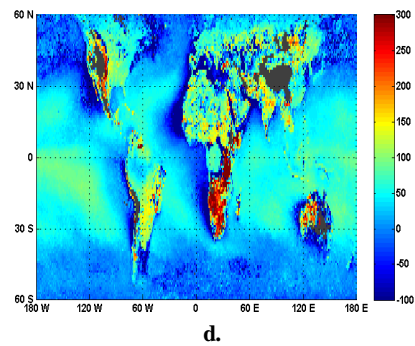

Figure 1. Global fields of yearly average 13:30 derived from AIRS sounder observations for 2003. (a) Bowen ratio $\beta$ $\left(\mathrm{W} \mathrm{m}^{-2} / \mathrm{W} \mathrm{m}^{-2}\right)$. (b) Net available energy, $\Phi\left(\mathrm{Wm}^{-2}\right)$. (c) Latent heat flux, $\lambda E\left(\mathrm{Wm}^{-2}\right)$. (d) Sensible heat flux, $H\left(\mathrm{Wm}^{-2}\right)$. Missing data are marked in grey.

Australia in summer 2003 (Feng et al., 2008) and hence this region is not covered particularly well.

The first thing to note from Fig. 1a is that there is a clear land-sea contrast with $\beta$ being relatively low and uniform over the sea as expected. The values of $\beta$ over the oceans are in the region of 0.1 , in line with commonly quoted figures for the sea (Betts and Ridgway, 1989; Hoen et al., 2002). Over the tropical forest regions of Amazonia and the Congo, $\beta$ is in the range of 0.1 to 0.3 , which also compares with values reported for these areas (da Rocha et al., 2004, 2009; Russell and Johnson, 2006). The more arid areas are also clearly delineated. Although somewhat variable, the Sahara gives a range of 1.5-3.5, which corresponds to the results of Kohler et al. (2010) and Wohlfahrt et al. (2009) for the Mojave Desert. The South American savanna gives a range between 0.5 and 1 , which corresponds to values reported by Giambelluca et al. (2009). One notable feature is the homogeneity of the $\beta$ fields over the Americas in contrast to the heterogeneity over Eurasia. The year 2003 was associated with widespread drying over Europe (Fink et al., 2004), which may explain this feature.

In an attempt to reassure the reader about the validity of the assumptions we are making, we have first tested the proposed methodology over a surface flux measurement site of SMEX02 experiment (Kustas et al., 2005) in the central United States, where both the radiosonde measurements and eddy covariance flux observations were available. The Bowen ratio was estimated from the air temperature and dewpoint temperature measurements of the radiosonde observations using the same methodology as described in the 


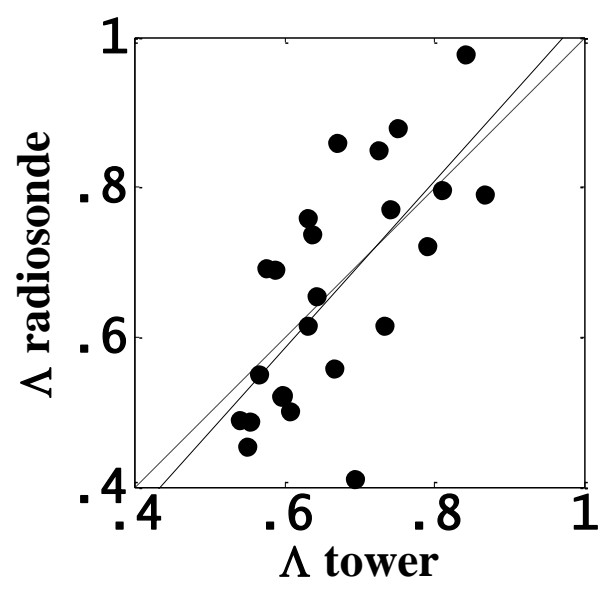

Figure 2. Evaluation of the radiosonde-derived evaporative fraction, $\Lambda$. This produces a correlation of $0.69\left(R^{2}=0.48\right)$ and a regression line (solid black line) of $\Lambda$ (radiosonde) $=$ $1.12( \pm 0.24) \Lambda$ (tower) $-0.08( \pm 0.16)$.

current manuscript. We have elected to evaluate $\beta$ in terms of evaporative fraction $(\Lambda)\left(=(1+\beta)^{-1}\right)$ (Shuttleworth et al., 1989) because, unlike $\beta, \Lambda$ is bounded and more linearly related to the tower fluxes from which it is derived $(\lambda E=\Lambda \Phi$, cf. Eq. 3). Figure 2 shows the relationship between the radiosonde- and tower-derived estimates of $\Lambda$ and reveals a fair degree of correspondence between the two. This analysis produces a significant and modest correlation $(r=$ $\left.0.69 \pm 0.10^{1}\right)$, reasonably low RMSE $(0.11)$ and mean absolute percent deviation (14\%) between radiosonde-derived $\Lambda$ and tower-observed $\Lambda$.

Figure $3 \mathrm{a}$ shows the relationship between the satelliteand tower-derived estimates of $\Lambda$. The evaluation in Fig. 3a reveals a significant correlation $\left(r=0.34 \pm 0.06^{1}\right)$ between $\Lambda$ (satellite) and $\Lambda$ (tower), albeit one corrupted by significant variability. This is to be expected given $\beta$ is defined as a ratio of either four uncertain soundings (for the satellite) or two uncertain fluxes (for the tower). Assuming both measures are co-related through some "true" intermediate-scale variable, then the slope and intercept of the regression relationship between the AIRS- and tower-observed $\Lambda$ are $0.31( \pm 0.02)$ and $0.49( \pm 0.04)$, respectively.

The sensitivity analysis results are given in Table 2 and show a differentially higher sensitivity to the vapour pressure observations than for temperature, and a standard deviation of 0.11 on the estimates of $\Lambda$ (satellite), although these results are dependent on the level of the input data given the inverse nonlinearity in Eq. (6).

\footnotetext{
${ }^{1}$ All uncertainties are expressed as \pm one standard deviation unless otherwise stated.
}

\subsection{Latent and sensible heat evaluation}

Figures $1 \mathrm{~b}$ and $3 \mathrm{~b}$ show the geographical distribution of the average noontime net available energy and its evaluation for the year 2003 taken from Mallick et al. (2014). The corresponding geographical distributions of $\lambda E$ and $H$ are shown in Fig. 1c and d. Figure $3 \mathrm{c}$ shows the relationship between the satellite and tower $\lambda E$ for all 30 evaluation sites. This gives an overall correlation of $r=0.75( \pm 0.04)$. Assuming both the tower and satellite data are linearly corelated, linear regression between the satellite and tower $\lambda E$ gave $\lambda E$ (satellite) $=0.98( \pm 0.02) \lambda E$ (tower) (offset not significant) with a root-mean-square deviation (RMSD) of $79 \mathrm{~W} \mathrm{~m}^{-2}$ (see Fig. 3c). The biome-specific statistics for $\lambda E$ are given in Table 3, which reveals correlations ranging from $r=0.41( \pm 0.22)$ (SAV, savanna) to $r=0.76( \pm 0.10)$ (ENF, evergreen needleleaf forest), RMSD ranging from 61 (MF) to 141 (SAV) $\mathrm{W} \mathrm{m}^{-2}$ and regression gains ranging from $0.85( \pm 0.08)$ (CRO, crops) to $2.00( \pm 0.28)$ (SAV). Higher correlations $(r=0.65-0.76)$ were evident over the forest sites where the tower height ranged from 40 to $65 \mathrm{~m}$, followed by moderate correlation over crops (CRO) and grasses (GRA) $(r=0.59-0.67)$ with tower height of $5-10 \mathrm{~m}$ (Table 3). Similarly, the slope of the correlation was close to unity for the forests and less than unity for CRO and GRA (Table 3) (Fig. 4). The only exception was found in savanna (SAV), which showed significant overestimation and low correlation (Table 3, Fig. 4; reasons discussed later).

The relationship between the satellite and tower $H$ for all 30 evaluation sites is shown in Fig. 3d. Here, $r=0.56( \pm 0.05)$ and the regression between the satellitepredicted and tower-observed $H$ produced a regression line of $H$ (satellite) $=0.59( \pm 0.02) H$ (tower) with an RMSD of $77 \mathrm{~W} \mathrm{~m}^{-2}$ for the pooled data. Again, the biome-specific statistics for $H$ are given in Table 3 and reveal correlations ranging from $0.43( \pm 0.15)$ (GRA) to $0.79( \pm 0.11)$ (CRO), RMSD ranging from 52 (CRO) to 149 (SAV) $\mathrm{W} \mathrm{m}^{-2}$ and regression gains ranging from $0.45( \pm 0.05)(\mathrm{SAV})$ to $0.93( \pm 0.06)$ (CRO). Figure 5 shows some examples of monthly time series of $\lambda E$ for both the satellite and the towers for a range of sites. This reveals that the seasonality in $\lambda E$ (tower) is relatively well captured in $\lambda E$ (satellite) in the majority of cases with the exception of Vielsalm, Tsukuba and Skukuza. Therefore, the individual site statistics given in Table 3 largely reflect the seasonality in the tower data.

The sensitivity-uncertainty results for $\lambda E$ are given in Table 2 , revealing a standard deviation on the estimate of $\lambda E$ from the ensemble of $60 \mathrm{~W} \mathrm{~m}^{-2}$ and significant sensitivity to the range of inputs used to calculate both $\beta$ and $\Phi$.

\section{Discussion}

The results in Fig. 3a may be interpreted through considering the effect of noise in the satellite sounding observations 


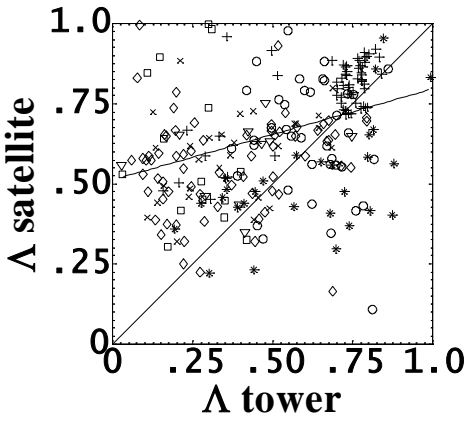

a.

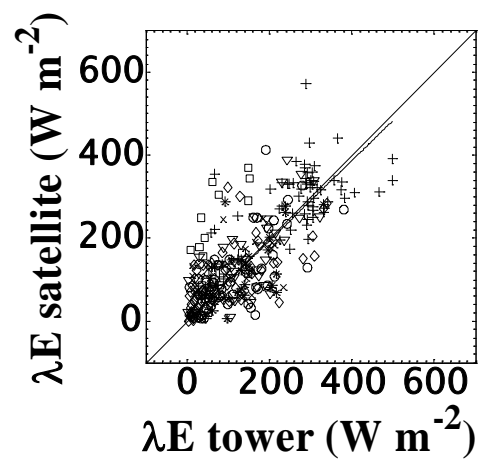

c.

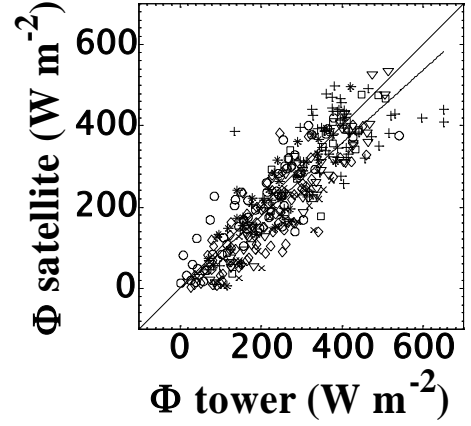

b.

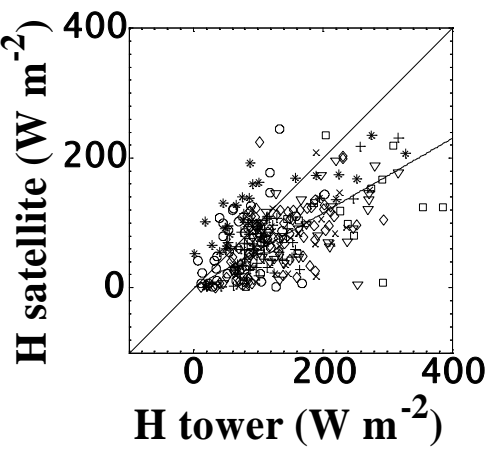

d.

Figure 3. The evaluation of the AIRS-derived monthly 13:30 surface flux components against their tower equivalent. (a) Evaporative fraction, $\Lambda$. Here, the solid regression line denotes $\Lambda$ (satellite $)=0.31( \pm 0.02) \Lambda$ (tower) $+0.49( \pm 0.04)$. (b) Net available energy, $\Phi$. Here, the solid regression line denotes $\Phi($ satellite $)=0.90( \pm 0.03) \Phi($ tower $)-2.43( \pm 8.19)$ (see Mallick et al., 2014). (c) Latent heat flux, $\lambda E$. (d) Sensible heat flux, $H$. For regression statistics see Table 3. The $1: 1$ line is shown for reference.

$(+\mathrm{EBF} ; \times \mathrm{MF} ; \bigcirc \mathrm{GRA} ; * \mathrm{CRO} ; \nabla \mathrm{ENF} ; \diamond \mathrm{DBF} ; \square \mathrm{SAV})$

EBF: evergreen broadleaf forest; MF: mixed forest; GRA: grassland; CRO: cropland; ENF: evergreen needleleaf forest; DBF: deciduous broadleaf forest; SAV: savanna

on the estimation of $\beta$ and hence $\Lambda$. From Table 2 we see the ensemble distribution of $\Lambda$ has a significant negative skew due to taking the inverse of the noise on $p_{1}$ and $p_{2}$ (cf. Eq. 6). As a result, there will be a tendency to overspecify $\Lambda$ from the sounding data given the "true" value will be less than the mode. Both the likelihood and the magnitude of this overspecification will increase as $p_{1}-p_{2} \rightarrow 0$ (i.e. as $\Lambda \rightarrow 0$ ) because of a decreasing signal-to-noise ratio. This explains why $\Lambda$ (satellite) and $\Lambda$ (tower) diverge as $\Lambda \rightarrow 0$. An additional reason for this divergence is provided by the fact that $H$ (satellite) $<H$ (tower) due to the effects of warm air entrainment (see later).

The retrieval of $\lambda E$ depends heavily on $\Phi$, hence the increase in the satellite-to-tower correlation seen for $\lambda E$ relative to $\Lambda$. Indeed, $\Lambda$ is a relatively stable characteristic within site, and so the variance of $\lambda E$ is dominated by seasonal and diurnal variations in $R_{\mathrm{N}}$ and $\Phi$ (da Rocha et al., 2004; Kumagai et al., 2005). For a detailed discussion of the efficacy of the satellite-derived values of $\Phi$ we have used here, the reader is referred to Mallick et al. (2014). To summarise, in comparing the satellite-derived $\Phi$ with the tower $H+\lambda E$, Mallick et al. (2014) found that their satellite estimate underestimated the tower value by, on average, approximately $10 \%$, i.e. $\Phi$ (satellite) $\approx 0.90 \Phi$ (tower) (see Fig. $3 b$ ). Therefore, the $2 \%$ underestimate in $\lambda E$ (satellite) seen here would indicate that we are getting an approximately $8 \%$ compensation error in $\lambda E$, introduced by the overspecification of $\Lambda$ (satellite) seen in Fig. 3a.

Given that there appears to be a widespread lack of energy balance closure of the order of $20 \%$ observed at most FLUXNET sites (Wilson et al., 2002), this implies a potential systematic underspecification of $\lambda E$ (tower) (and/or $H$ (tower)). However, by the same argument the evaluation between satellite and tower for $\Phi$ would change by a similar amount, leading to little or no net change in the overall evaluation for $\lambda E$. Mallick et al. (2014) found that accommodating a $20 \%$ imbalance in $\Phi$ (tower) gave $\Phi$ (satellite) $\approx 0.72 \Phi$ (tower) and that this lack of agreement could be ex- 
Table 2. Sensitivity analysis results of $\Lambda, \Phi$ and $\lambda E$. The forcing data are taken for mid-summer, Southern Great Plains, US. Sensitivities are locally linear-averaged across the ensemble response and expressed as dimensionless relative changes. Only absolute sensitivities $>0.1$ are shown. $N=10^{5}$ realisations.

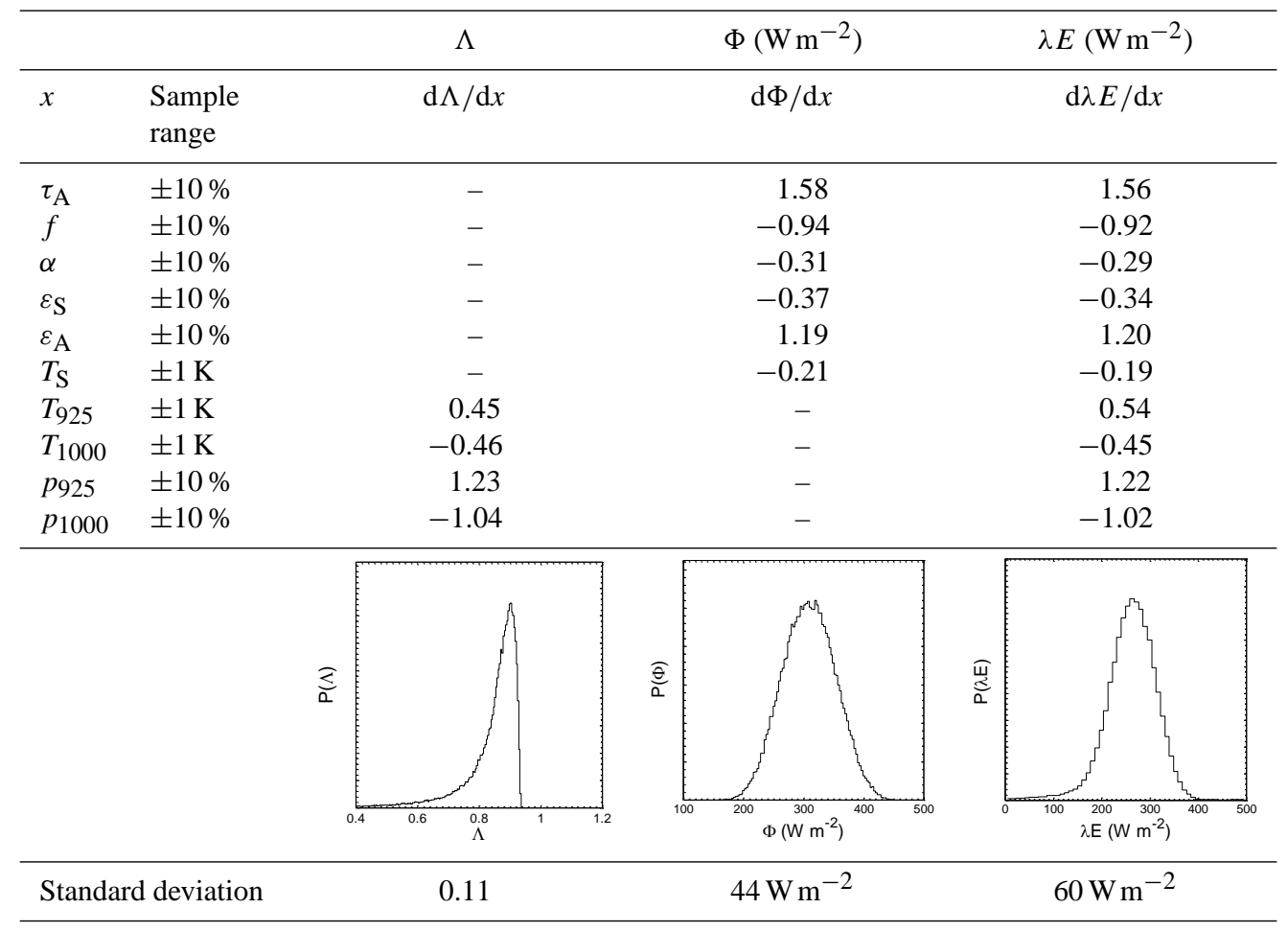

$\tau_{\mathrm{A}}:$ atmospheric transmissivity; $f$ : cloud cover fraction; $\alpha$ : surface albedo; $\varepsilon_{\mathrm{S}}$ : surface emissivity; $\varepsilon_{\mathrm{A}}:$ air emissivity; $T_{\mathrm{S}}$ : land surface temperature; $T_{925}$ : air temperature at $925 \mathrm{mb}$ sounding; $T_{1000}$ : air temperature at $1000 \mathrm{mb}$ sounding; $p_{925}$ : partial pressure of water vapour at $925 \mathrm{mb}$ sounding; $p_{1000}$ : partial pressure of water vapour at $1000 \mathrm{mb}$ sounding.

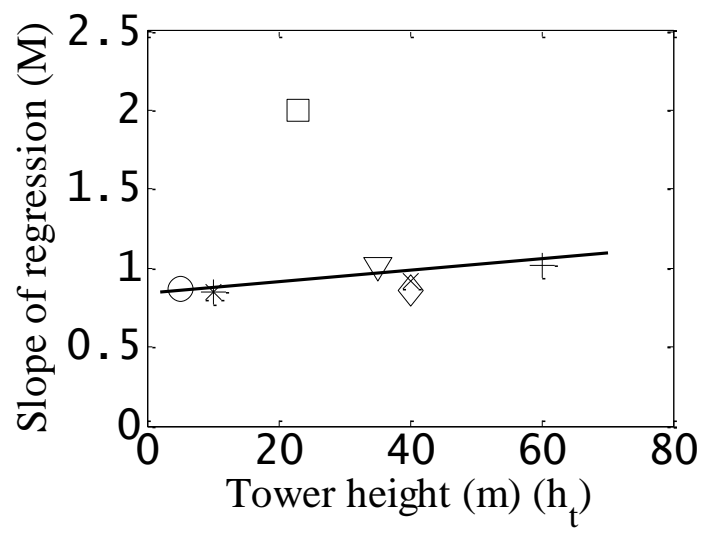

Figure 4. Scatter plot showing the slope of regression $(M)$ between the observed and estimated $\lambda E$ as a function of the corresponding $\lambda E$ measurement height (tower height, $h_{\mathrm{t}}$ ) for different biome classes. The tower heights of similar biomes are averaged. The solid line is the best-fit relationship $\left(M=0.003 h_{\mathrm{t}}+0.84, R^{2}=0.46\right)$ after removing the SAV biome type. This shows that $M$ approaches unity with $h_{\mathrm{t}}$.

$(+\mathrm{EBF} ; \times \mathrm{MF} ; \bigcirc \mathrm{GRA} ; * \mathrm{CRO} ; \nabla \mathrm{ENF} ; \diamond \mathrm{DBF} ; \square \mathrm{SAV})$ plained by the underspecification of the downwelling shortwave radiation component of $\Phi$ (satellite). It is unlikely that the entire energy imbalance is attributable solely to $\lambda \mathrm{E}$ (tower) (Foken, 2008). As a result, the likely range for the pooled gain between the satellite and tower $\lambda E$ is between 0.8 and 1.0 , determined by the combination of underspecification of the satellite downwelling shortwave combined with overspecification of satellite $\Lambda$.

The monthly infrared products of AIRS are, by definition, a sample of relatively cloud-free conditions whilst the tower fluxes are for a mixture of clear and cloudy atmospheric conditions. The inclusion/omission of cloudy conditions should have little or no impact on energy partitioning ratios such as $\beta$ (Grimmond and Oke, 1995; Balogun et al., 2009). Furthermore, despite being biased low, the shortwave component of $\Phi$ specified by Mallick et al. (2014) was for all-sky conditions, whilst the IR components of $\Phi$ appeared to be somewhat insensitive to the clear-sky sampling bias. As a result, the primary motivation for attempting to recover satellite estimates for all-sky conditions would appear to be for increasing the temporal resolution of the data, and not for removing bias from the monthly satellite estimates.

The landscape-scale $\beta$ (and hence $\Lambda$ ) estimated from sounder data relate to a location some few hundred metres 
Table 3. Error analysis of AIRS-derived $\lambda E$ and $H$ over diverse plant functional types (biomes) of the FLUXNET eddy covariance network. Values in the parenthesis are \pm 1 standard deviation unless otherwise stated.

\begin{tabular}{|c|c|c|c|c|c|c|c|c|c|}
\hline \multirow[b]{2}{*}{ Biome } & \multirow[b]{2}{*}{$\begin{array}{c}\text { Average } \\
\text { tower height } \\
(\mathrm{m})\end{array}$} & \multicolumn{4}{|c|}{$\lambda E$} & \multicolumn{4}{|c|}{$H$} \\
\hline & & $\begin{array}{c}\text { RMSD } \\
\left(\mathrm{Wm}^{-2}\right)\end{array}$ & Slope & $r$ & $N$ & $\begin{array}{c}\text { RMSD } \\
\left(\mathrm{Wm}^{-2}\right)\end{array}$ & Slope & $r$ & $N$ \\
\hline EBF & 60 & 84.84 & $\begin{array}{c}1.02 \\
( \pm 0.04)\end{array}$ & $\begin{array}{c}0.70 \\
( \pm 0.09)\end{array}$ & 65 & 53.2 & $\begin{array}{c}0.64 \\
( \pm 0.03)\end{array}$ & $\begin{array}{c}0.73 \\
( \pm 0.09)\end{array}$ & 66 \\
\hline MF & 40 & 60.66 & $\begin{array}{c}0.92 \\
( \pm 0.09)\end{array}$ & $\begin{array}{c}0.65 \\
( \pm 0.14)\end{array}$ & 32 & 87.9 & $\begin{array}{c}0.50 \\
( \pm 0.04)\end{array}$ & $\begin{array}{c}0.67 \\
( \pm 0.14)\end{array}$ & 30 \\
\hline GRA & 5 & 78.39 & $\begin{array}{c}0.87 \\
( \pm 0.08)\end{array}$ & $\begin{array}{c}0.67 \\
( \pm 0.12)\end{array}$ & 42 & 55.82 & $\begin{array}{c}0.79 \\
( \pm 0.09)\end{array}$ & $\begin{array}{c}0.43 \\
( \pm 0.15)\end{array}$ & 39 \\
\hline $\mathrm{CRO}$ & 10 & 69.76 & $\begin{array}{c}0.85 \\
( \pm 0.08)\end{array}$ & $\begin{array}{c}0.59 \\
( \pm 0.15)\end{array}$ & 31 & 51.74 & $\begin{array}{c}0.93 \\
( \pm 0.06)\end{array}$ & $\begin{array}{c}0.79 \\
( \pm 0.11)\end{array}$ & 31 \\
\hline ENF & 35 & 67.64 & $\begin{array}{c}1.02 \\
( \pm 0.07)\end{array}$ & $\begin{array}{c}0.76 \\
( \pm 0.10)\end{array}$ & 43 & 95.14 & $\begin{array}{c}0.52 \\
( \pm 0.04)\end{array}$ & $\begin{array}{c}0.62 \\
( \pm 0.13)\end{array}$ & 37 \\
\hline DBF & 40 & 65.19 & $\begin{array}{c}0.86 \\
( \pm 0.06)\end{array}$ & $\begin{array}{c}0.68 \\
( \pm 0.09)\end{array}$ & 74 & 73.19 & $\begin{array}{c}0.59 \\
( \pm 0.04)\end{array}$ & $\begin{array}{c}0.49 \\
( \pm 0.11)\end{array}$ & 70 \\
\hline SAV & 23 & 140.78 & $\begin{array}{c}2.00 \\
( \pm 0.28)\end{array}$ & $\begin{array}{c}0.41 \\
( \pm 0.22)\end{array}$ & 19 & 148.52 & $\begin{array}{c}0.45 \\
( \pm 0.05)\end{array}$ & $\begin{array}{c}0.51 \\
( \pm 0.22)\end{array}$ & 18 \\
\hline Pooled & - & 78.74 & $\begin{array}{c}0.98 \\
( \pm 0.02)\end{array}$ & $\begin{array}{c}0.75 \\
( \pm 0.04)\end{array}$ & 306 & 76.94 & $\begin{array}{c}0.59 \\
( \pm 0.02)\end{array}$ & $\begin{array}{c}0.56 \\
( \pm 0.05)\end{array}$ & 291 \\
\hline
\end{tabular}

$N$ : number of data points falling under each biome category.

EBF: evergreen broadleaf forest; MF: mixed forest; GRA: grassland; CRO: cropland; ENF: evergreen needleleaf forest; DBF: deciduous broadleaf forest; SAV: savanna.

above the surface, whilst the tower data relate to heights either metres (for GRA, CRO and SAV) or tens of metres (for EBF, MF, DF, EF) above the surface. These towers are designed to operate in the constant flux portion of the planetary boundary layer which, as a rule of thumb, occupies the lower $10 \%$ of the planetary boundary layer and where fluxes change by less than $10 \%$ with height (Stull, 1988). Above this layer there is a tendency of $H$ to decrease with height due to the entrainment of warm air from aloft down into the mixed layer (Stull, 1988). This could partly explain the results in Fig. 3d, where $H$ (satellite) is significantly less than $H$ (tower). In contrast, $\lambda E$ often tends to be preserved with height by the entrainment dry air from aloft (Stull, 1988; Mahrt et al., 2001). While comparing ground eddy covariance fluxes with aircraft fluxes over diverse European regions, Gioli et al. (2004) found the value of $H$ at an average height of $70 \mathrm{~m}$ was $35 \%$ less that those at ground level, whereas no such trend in $\lambda E$ was observed. Similarly, Miglietta et al. (2009) found $H$ lapsed by $36 \%$ as one moved from the surface to a height of $100 \mathrm{~m}$. The same behaviour has also been frequently observed in both airborne and ground-based eddy covariance measurements in the USA (e.g. Desjardins et al., 1992) and Europe (Torralba et al., 2008; Miglietta et al., 2009). Because of the differing lapse properties of $\lambda E$ and $H$, one would imagine $\Lambda$ (satellite) should, on average, be more than $\Lambda$ (tower), which, despite being somewhat uncertain, is what we observe both in Figs. 2 and $3 \mathrm{a}$.
The Bowen ratio method has been seen to break down under hot, dry conditions. This is due to large-scale regionally advected sensible heat desaturating the surface and causing the vertical vapour pressure gradient to reverse (Perez et al., 1999), a condition that appeared to persist in the AIRS soundings over central Australia throughout the summer of 2003. Under these conditions $k_{\mathrm{H}}$ can become 2 to 3 times higher than $k_{\mathrm{E}}$, so that $k_{\mathrm{E}} \neq k_{\mathrm{H}}$ (Verma et al., 1978; Katul et al., 1995). Although we rejected all samples characterised by a reversal of the AIRS vapour pressure gradient, a tendency for $\Lambda$ (satellite) $<\Lambda$ (tower) should be observed in the data particularly for the drier biomes. However, for the SAV data $\Lambda$ (satellite) $>\Lambda$ (tower) on average (see Fig. 3a), indicating this is not a dominant effect.

The satellite-derived fluxes aggregate sub-grid heterogeneity (surface geometry, roughness, vegetation index, land surface temperature, surface wetness, albedo, etc.) at the $10000 \mathrm{~km}^{2}$, whereas the towers aggregate at scales of $\sim$ $1 \mathrm{~km}^{2}$. This mismatch on the scale of approximately four orders of magnitude is an important potential source of disagreement between the satellite- and tower-observed fluxes. Although towers are often installed in relatively homogenous terrain at the local scale, rarely can this be assumed for scales approaching the AIRS data. In addition, characteristics such as surface wetness and temperature can still be highly heterogeneous at the local tower scale (Kustas and Norman, 1999; McCabe and Wood, 2006; Li et al., 2008) whilst also exerting significant nonlinear effects on $\lambda E$ (Nykanen 

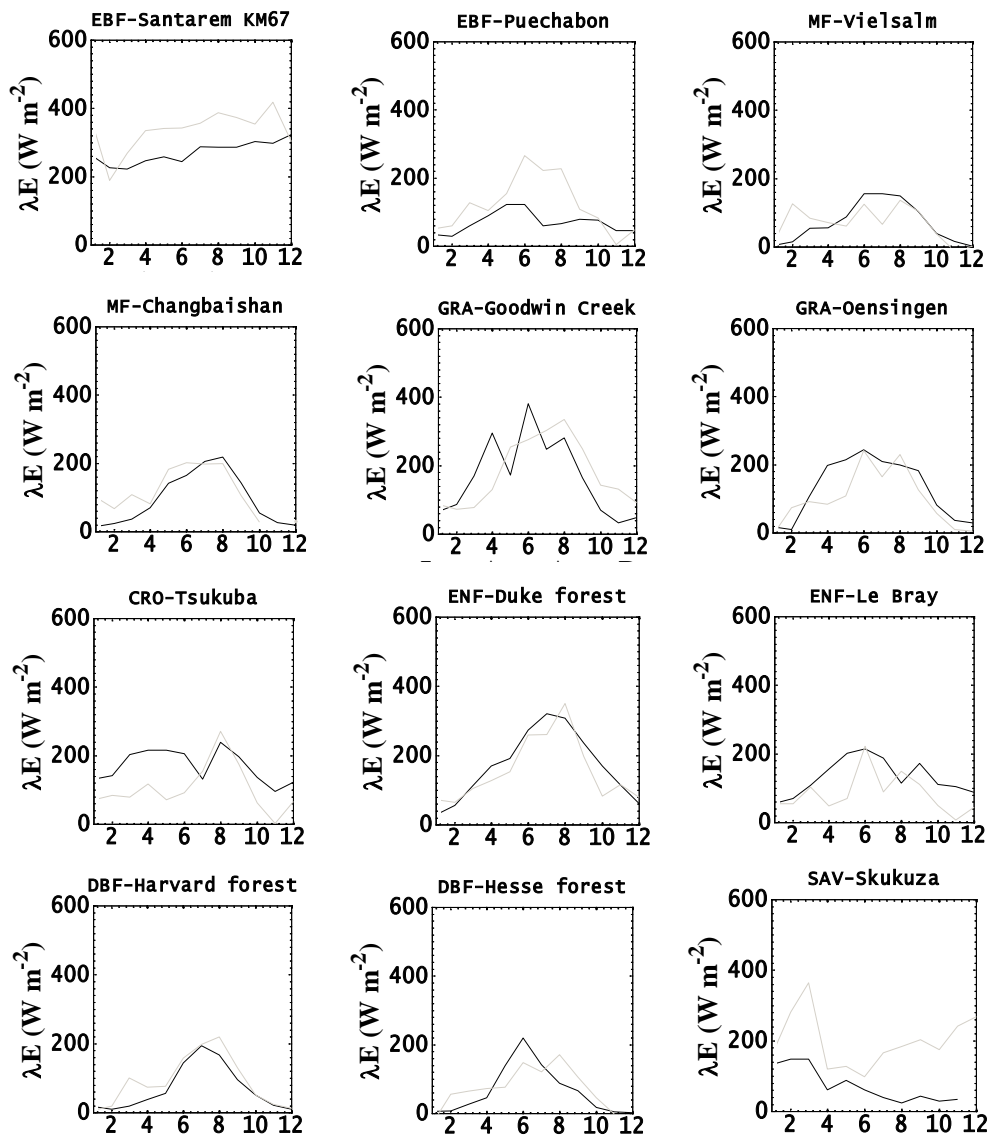

Figure 5. Satellite (grey) and tower (black) time series of monthly average 13:30 latent heat flux, $\lambda E$, for a selection of sites for 2003. The numbers on the $x$ axis are the month numbers, indicating January ( month number 1) to December (month number 12).

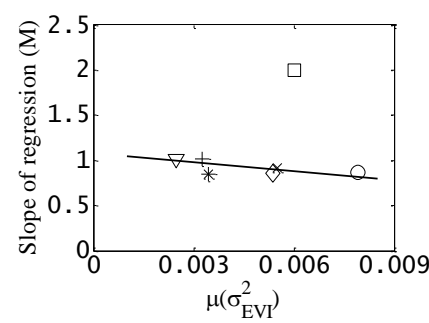

(a)

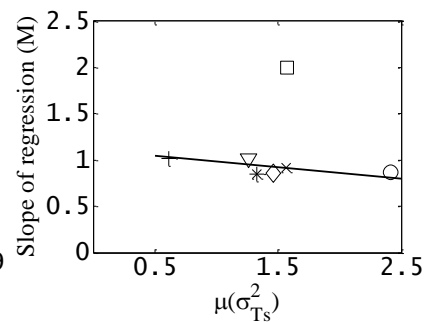

(b)
Figure 6. (a, b) Scatter plot showing the slope of regression between the observed and estimated $\lambda E$ as a function of the mean variance of EVI and $T_{\mathrm{S}}$ for a $10 \mathrm{~km} \times 10 \mathrm{~km}$ area surrounding the tower sites of each biome categories. Variances of individual sites falling under each biome are averaged. The solid lines are the best-fit relationships $\left(M=-23.90 \mu\left(\sigma_{\mathrm{EVI}}^{2}\right)+1.03, R^{2}=0.37\right.$; $\left.M=-0.08 \mu\left(\sigma_{\mathrm{T}_{\mathrm{S}}}^{2}\right)+1.04, R^{2}=0.39\right)$ after removing the SAV biome type. This shows $M$ approaches unity with increasing homogeneity.

$(+\mathrm{EBF} ; \times \mathrm{MF} ; \bigcirc \mathrm{GRA} ; * \mathrm{CRO} ; \nabla \mathrm{ENF} ; \diamond \mathrm{DBF} ; \square \mathrm{SAV})$ and Georgiou, 2001). If, for example, the probability of a tower being located in either a cool/wet or hot/dry patch is even, and yet the cool/wet regions contribute disproportionately to the satellite-scale latent heat flux, then, on average, there clearly is a tendency for the tower-observed flux to be less than its satellite counterpart (Bastiaanssen et al., 1997). Because of the diversity of nonlinear surface characteristics effects on $\lambda E$, a detailed evaluation of the scaling characteristics of $\lambda E$ lies beyond the scope of this paper. However the slope of the regression between the observed and estimated $\lambda E$ of individual biome category was significantly related to the average variance of EVI (enhanced vegetation index) $\left[\mu\left(\sigma_{\mathrm{EVI}}^{2}\right)\right]$ and $T_{\mathrm{S}}$ (land surface temperature) $\left[\mu\left(\sigma_{T_{\mathrm{S}}}^{2}\right)\right]$ for a $10 \mathrm{~km} \times 10 \mathrm{~km}$ area surrounding the tower sites (Fig. 6a and b) $\left(R^{2}=0.37\right.$ and 0.39 , respectively). The slope of regression varied systematically with the landscape heterogeneity and the results are in agreement with Stoy et al. (2013), who also found a systematic relationship between the surface energy balance closure and landscape heterogeneity over 173 FLUXNET tower sites. One general inference can be drawn, however; the degree of agreement we see in the pooled evaluation would suggest that the spatial scaling from 
tower to satellite appears somewhat conserved, a feature that is no doubt greatly aided by investigating the monthly average data where the effects of dynamic spatial heterogeneity (e.g. in surface wetness and surface temperature) will tend to have been averaged out. However the results in Table 3 and Fig. 4 suggest that the data from the taller, more extensive forest towers are more closely related to their satellite counterparts, although the higher correlations may also reflect the dominance of net radiation in driving latent heat flux over these sites.

The pooled RMSD of $79 \mathrm{~W} \mathrm{~m}^{-2}$ for the $\lambda E$ evaluation is comparable with the results reported elsewhere. Mecikalski et al. (1999) reported RMSEs in daily $\lambda E$ estimates in the range of 37 to $59 \mathrm{~W} \mathrm{~m}^{-2}$ while estimating continental scale fluxes over the USA using GOES (Geostationary Operational Environmental Satellite) data. Anderson et al. (2008) reported an RMSD for instantaneous $\lambda E$ estimates of $79 \mathrm{~W} \mathrm{~m}^{-2}$ using a Bowen Ratio closure method and $66 \mathrm{~W} \mathrm{~m}^{-2}$ using the residual surface energy balance method. Another study of Anderson et al. (2007) reported an RMSD in hourly $\lambda E$ of $58 \mathrm{~W} \mathrm{~m}^{-2}$ using $10 \mathrm{~km}^{2}$ scale GOES data over Iowa, although this reduced to $1.7 \mathrm{~W} \mathrm{~m}^{-2}$ when considering cumulative daily data. Jiang et al. (2009) reported an RMSD of $23-40 \mathrm{~W} \mathrm{~m}^{-2}$ for daily $\lambda E$ retrievals using NOAA (National Oceanic and Atmospheric Administration) AVHRR (Advanced Very High Resolution Radiometer) data over southern Florida. Interestingly, they also found a significant negative correlation between satellite and ground-truth evaporative fraction. Jiang and Islam (2001) and Batra et al. (2006) reported RMSDs for noontime $\lambda E$ retrievals from a series of studies over the Southern Great Plains of the USA in the range of 25 to $97 \mathrm{~W} \mathrm{~m}^{-2}$ using moderate-resolution NOAA-16, NOAA-14 and MODIS-Terra optical and thermal data. In addressing the effects of scaling and surface heterogeneity issues on $\lambda E$, McCabe and Wood (2006) obtained an RMSD of $64 \mathrm{Wm}^{-2}$ when comparing spatially aggregated LANDSAT (Land Remote-Sensing Satellite)-derived instantaneous $\lambda E$ and MODIS Terra $\lambda E$ in central Iowa. Finally, using the surface temperature vs. vegetation index triangle approach with MSG (Meteosat Second Generation) SEVIRI (Spinning Enhanced Visible and Infrared Imager) data, Stisen et al. (2008) obtained an RMSD of $41 \mathrm{Wm}^{-2}$ for daily data over the Senegal River basin. Finally, Prueger et al. (2005) obtained a disagreement of $45 \mathrm{~W} \mathrm{~m}^{-2}$ in instantaneous noontime $\lambda E$ while comparing $40 \mathrm{~m}$ aircraft and $2 \mathrm{~m}$ ground eddy covariance $\lambda E$ measurements again in central Iowa. Some additional studies also reported RMSDs of monthly fluxes (for example, Cleugh et al., 2007; Mu et al., 2011). In these studies, daily $\lambda E$ was modelled using daily radiation and meteorological variables and monthly fluxes were generated from the daily averages. Cleugh et al. (2007) reported RMSD of $27 \mathrm{~W} \mathrm{~m}^{-2}$ over two contrasting sites in Australia using tower meteorology and MODIS vegetation index over the eddy covariance footprints. $\mathrm{Mu}$ et al. $(2007,2011)$ reported an RMSD of $8-180 \mathrm{~W} \mathrm{~m}^{-2}$ on 8day average $\lambda E$ and $12 \mathrm{~mm}$ on monthly average $\lambda E$.

\section{Conclusions}

We conclude that the combination of the satellite sounding data and the Bowen ratio methodology shows significant promise for retrieving spatial fields of $\lambda E$ when compared with tower ground-truth data, and warrants further investigation and refinement. The specification of satellite net available energy, and its shortwave component in particular, requires further attention. There are also circumstances where the satellite Bowen ratio method is inapplicable, but these conditions could be easily flagged by internal checks on the sounding profiles. Where the method appears to work, this provides estimates of $\lambda E$ that would prove valuable in a range of applications. In particular, because no land surface model has been involved in their derivation, the estimates of $\lambda E$ we show can be used as independent data for evaluating land surface parameterisations in a broad range of spatially explicit hydrology, weather and climate models. Furthermore, the availability of sounding data at both $1^{\circ}$ and $5 \mathrm{~km}$ resolution in conjunction with tower and scintillometer surface flux data would provide an excellent opportunity to explore robust scaling methods in these same models.

Given that the Bowen ratio method should work best in the non-limiting water environments, the sea estimates of latent heat we show here are potentially more reliable than their terrestrial counterparts.

The advent of microwave sounding platforms such as Megha-Tropiques may afford an opportunity to extend the methodology to persistent overcast conditions, allowing for more detailed process studies. This approach could also exploit high spatial and temporal resolution geostationary sounder platforms like GOES and, in the near future, GIFTS (Geosynchronous Interferometric Fourier Transform Spectrometer) and INSAT (Indian National Satellite)-3D. We also expect that the high vertical resolution soundings these platforms will provide will improve the accuracy of the current approach, particularly over elevated terrain.

Acknowledgements. We would like to acknowledge Goddard Earth Sciences Data and Information Services Center (GESS - DISC) and Atmosphere Archive and Distribution System (LAADS) web interface, NASA, for making the AIRS and MODIS data available. We gratefully acknowledge all the site PIs who provided terrestrial flux data through the FLUXNET La Thuile data archive. The AmeriFlux regional network component of this archive is supported with funding from the US Department of Energy under its Terrestrial Carbon project. We also acknowledge National Snow and Ice Data Center (NSIDC) for the SMEX02 radiosonde data. This work was supported by Natural Environment Research Council (NERC) grant NEE0191531. We thank Paul Stoy, Montana State University, for valuable suggestions that helped in improving the manuscript. The authors declare no conflict of interest. 
Edited by: P. Stoy

\section{References}

Anderson, M. C., Norman, J. M., Mecikalski, J. R., Otkin, J. P., and Kustas, W. P.: A climatological study of evapotranspiration and moisture stress across the continental U.S. based on thermal remote sensing: I. Model formulation, J. Geophys. Res., 112, D11112, doi:10.1029/2006JD007506, 2007.

Anderson, M. C., Norman, J. M., Kustas, W. P., Houborg, R., Starks, P. J., and Agam, N.: A thermal-based remote sensing technique for routine mapping of land-surface carbon, water and energy fluxes from field to regional scales, Remote Sens. Environ., 112, 4227-4241, 2008.

Aumann, H. H., Chahine, M. T., Gautier, C., Goldberg, M. D., Kalnay, E., McMillin, L. M., Revercomb, H., Rosenkranz, P. W., Smith, W. L., Staelin, D. H., Strow, L. L., and Susskind, J.: AIRS/AMSU/HSB on the aqua mission: design, science objectives, data products and processing systems, IEEE T. Geosci. Remote, 41, 253-264, 2003.

Baldocchi, D. D., Falge, E., Gu, L., Olson, R., Hollinger, D., Running, S., Anthoni, P., Bernhofer, C., Davis, K., Evans, R., Fuentes, J., Goldstein, A., Katul, G., Law, B., Lee, X., Malhi, Y., Meyers, T., Munger, W., Oechel, W., Paw, U. K. T., Pilegaard, K., Schmid, H. P., Valentini, R., Verma, S., Vesala, T., Wilson, K., and Wofsy, S.: Fluxnet: a new tool to study the temporal and spatial variability of ecosystem-scale carbon dioxide, water vapor, and energy flux densities, B. Am. Meteorol. Soc., 82, 24153434, 2001.

Balogun, A. A., Adegoke, J. O., Vezhapparambu, S., Mauder, M., McFadden, J. P., and Gallo, K.: Surface energy balance measurements above an exurban residential neighbourhood of Kansas City, Missouri, Bound.-Lay. Meteorol., 133, 299-321, 2009.

Bastiaanssen, W. G. M., Pelgrum, H., Droogers, P., de Bruin, H. A. R., and Menenti, M.: Area-average estimates of evaporation, wetness indicators and top soil moisture during two golden days in EFEDA , Agr. Forest Meteorol., 87, 119-137, 1997.

Bastiaanssen, W. G. M., Menenti, M., Feddes, R. A., and Holtslag, A. A. M.: The Surface Energy Balance Algorithm for Land (SEBAL): Part 1 formulation, J. Hydrol., 212-213, 198-212, 1998.

Batra, N., Islam, S., Venturini, V., Bisht, G., and Jiang, L.: Estimation and comparison of evapotranspiration from MODIS and AVHRR sensors for clear sky days over the southern great plains, Remote Sens. Environ., 103, 1-15, 2006.

Betts, A. K. and Ridgway, W.: Climate equilibrium of the atmospheric convective boundary layer over a tropical ocean, J. Atmos. Sci., 46, 2621-2641, 1989.

Bowen, I. S.: The ratio of heat losses by conduction and by evaporation from any water surface, Phys. Rev., 27, 779-787, 1926.

Brennan, M. J. and Lackmann, G. M.: The influence of incipient latent heat release on the precipitation distribution of the 24-25 January 2000 U.S. East Coast cyclone, Mon. Weather Rev., 133, 1913-1937, 2005.

Campbell Scientific: Bowen Ratio instrumentation instruction manual, Campbell Scientific Inc., Logan, Utah, 1-2, 2005.

Chen, F. and Dudhia, J.: Coupling an advanced land surfacehydrology model with the Penn State-NCAR MM5 model- ing system. part I: model implementation and sensitivity, Mon. Weather Rev., 129, 569-585, 2001.

Choudhury, B. J. and DiGirolamo, N.: A biophysical process-based estimate of global land surface evaporation using satellite and ancillary data I. Model description and comparison with observations, J. Hydrol., 205, 164-185, 1998.

Cleugh, H. A., Leuning, R., Mu, Q., and Running, S. W.: Regional evaporation estimates from flux tower and MODIS satellite data, Remote Sens. Environ., 106, 285-304, 2007.

da Rocha, H. R., Goulden, M. L., Miller, S. D., Menton, M. C., Pinto, L. D. V. O., De Freitas, H. C., and Silva Figueira, A. M. E.: Seasonality of water and heat fluxes over a tropical forest in eastern Amazonia, Ecol. Appl., 14, s22-s32, 2004.

da Rocha, H. R., Manzi, A. O., Cabral, O. M., Miller, S. D., Goulden, M. L., Saleska, S. R., Coupe, N. R., Wofsy, S. C., Borma, L. S., Artaxo, P., Vourlitis, G., Nogueira, J. S., Cardoso, F. L., Nobre, A. D., Kruijt, B., Freitas, H. C., von Randow, C., Aguiar, R. G., and Maia, J. F.: Patterns of water and heat flux across a biome gradient from tropical forest to savanna in Brazil, J. Geophys. Res., 114, G00B12, doi:10.1029/2007JG000640, 2009.

Desjardins, R. L., Hart, R. L, Macpherson, J. I., Schuepp, P. H., and Verma, S. B.: Aircraft-based and tower-based fluxes of carbondioxide, latent, and sensible heat, J. Geophys. Res., 97, $18477-$ 18485,1992

Dyer, A. J.: A review of flux profile relationships, Bound.-Lay. Meteorol., 7, 363-372, 1974.

Feng, M., Biastoch, A., Böning, C., Caputi, N., and Meyers, G.: Seasonal and interannual variations of upper ocean heat balance off the west coast of Australia, J. Geophys. Res., 113, C12025, doi:10.1029/2008JC004908, 2008.

Fink, A. H., Brücher, T., Krüger, A., Leckebusch, G. C., Pinto, J. G., and Ulbrich, U.: The 2003 European summer heatwaves and drought - synoptic diagnosis and impacts, Weather, 59, 209216, 2004.

Fisch, G., Tota, J., Machado, L. A. T., Silva Dias, M. A. F., da F. Lyra, R. F., Nobre, C. A., Dolman, A. J., and Gash, J. H. C.: The convective boundary layer over pasture and forest in Amazonia, Theor. Appl. Climatol., 78, 47-59, 2004.

Fisher, J. B., Tu, K., and Baldocchi, D. D.: Global estimates of landatmosphere water flux based on monthly AVHRR and ISLSCPII data, validated at 16 FLUXNET sites, Remote Sens. Environ., 112, 901-919, 2008.

Foken, T.: The energy balance closure problem: an overview, Ecol. Appl. 18, 1351-1367, 2008.

Foken, T., Wimmer, F., Mauder, M., Thomas, C., and Liebethal, C.: Some aspects of the energy balance closure problem, Atmos. Chem. Phys., 6, 4395-4402, doi:10.5194/acp-6-4395-2006, 2006.

Fritschen, L. J. and Fritschen, C. L.: Bowen ration energy balance method, in: Micrometeorology in Agricultural Systems, edited by: Hatfield, J. L. and Baker, J. M., American Soc. Agronomy, Madison, Wisconsin, USA, 397-406, 2005

Fritschen, L. J. and Simpson, J. R.: Surface energy and radiation balance systems: general description and improvements, J. Appl. Meteorol., 28, 680-689, 1989.

Giambelluca, T. W., Scholz, F. G., Bucci, S., Meinzer, F. C., Goldstein, G., Hoffmann, W. A., Franco, A. C., and Buchert, M. P.: Evapotranspiration and energy balance of Brazilian savannas 
with contrasting tree density, Agr. Forest Meteorol., 149, 13651376, 2009.

Gioli, B., Miglietta, F., Martino, B. D., Hutjes, R. W. A., Dolman, H. A. J., Lindroth, A., Schumacher, M., Sanz, M. J., Manca, G., Peressotti, A., and Dumas, E. J.: Comparison between tower and aircraft-based eddy covariance fluxes in five European regions, Agr. Forest Meteorol., 127, 1-16, 2004.

Goddard Earth Sciences Data and Information Services Centr, available at: http://mirador.gsfc.nasa.gov/.

Grimmond, C. S. B. and Oke, T. R.: Comparison of heat fluxes from summertime observations in the suburbs of four north American cities, J. Appl. Meteorol., 34, 873-889, 1995.

Hoen, J. O. Y., Hai, Y. X., Pan, J., Xia, H. M., and Liu, T. W.: Calculation of the Bowen ratio in the tropical Pacific using sea surface temperature data, J. Geophys. Res., 107, 17.1-17.16, 2002.

Hsu, S. A.: A relationship between the Bowen Ratio and sea-air temperature difference under unstable conditions at sea, J. Phys. Oceanogr., 28, 2222-2226, 1998.

Irannejad, P., Henderson-Sellers, A., and Sharmeen, S.: Importance of land-surface parameterization for latent heat simulation in global atmospheric models, Geophys. Res. Lett., 30, 1904, doi:10.1029/2003GL018044, 2003.

Jang, K., Kang, S., Kim, J., Lee, C. B., Kim, T., Kim, J., Hirata, R., and Saigusa, N.: Mapping evapotranspiration using MODIS and MM5 Four-Dimensional Data Assimilation, Remote Sens. Environ., 114, 657-673, 2010.

Jiang, L. and Islam, S.: Estimation of surface evaporation map over southern Great Plains using remote sensing data, Water Resour. Res., 37, 329-340, 2001.

Jiang, L., Islam, S., Guo, W., Jutla, A. S., Senarath, S. U. S., Ramsay, B. H., and Eltahir, E.: A satellite-based Daily Actual Evapotranspiration estimation algorithm over South Florida, Global Planet. Change, 67, 62-77, 2009.

Jiminez, C., Prigent, C., and Aries, F.: Towards an estimation of global land surface heat fluxes from multisatellite observations, J. Geophys. Res., 114, D06305, doi:10.1029/2008JD011392, 2009.

Katul, G., Goltz, S., Hsieh, C.-I., Cheng, Y., Mowry, F., and Sigmon, J.: Estimation of surface heat and momentum fluxes using the flux-variance method above uniform and non-uniform terrain, Bound.-Lay. Meteorol., 74, 237-260, doi:10.1007/BF00712120, 1995.

Kohler, M., Kalthoff, N., and Kottmeier, C.: The impact of soil moisture modifications on CBL characteristics in West Africa: A case-study from the AMMA campaign, Q. J. Roy. Meteorol. Soc., 136, 442-455, 2010.

Konda, M.: The satellite-derived air temperature and the Bowen ratio over the ocean, in: 35th COSPAR Scientific Assembly, 18-25 July 2004, Paris, France, p. 1839, 2004.

Kumagai, T., Saitoh, T. M., Sato, Y., Takahashi, H., Manfroi, O. J., Morooka, T., Kuraji, K., Suzuki, M., Yasunari, T., and Komatsu, H.: Annual water balance and seasonality of evapotranspiration in a Bornean tropical rainforest, Agr. Forest Meteorol., 128, 8192, 2005.

Kustas, W. P. and Norman, J. M.: Evaluating the effects of subpixel heterogeneity on pixel average fluxes, Remote Sens. Environ., 74, 327-342, 1999.

Kustas, W. P., Hatfield, J. L., and Prueger, J. H.: The Soil Moisture Atmosphere Coupling Experiment (SMACEX): Background, hydrometeorological conditions and preliminary findings, J. Hydrometeorol., 6, 791-804, 2005.

Lawford, R. G., Stewart, R., Roads, J., Isemer, H.-J., Manton, M., Marengo, J., Yasunari, T., Benedict, S., Koike, T., and Williams, S.: Advancing global and continental scale hydrometeorology: Contributions of the GEWEX Hydrometeorology Panel, B. Am. Meteorol. Soc., 85, 1917-1930, 2004.

Lehner, B., Döll, P., Alcamo, J., Henrichs, T., and Kaspar, F.: Estimating the impact of global change on flood and drought risks in Europe: a continental, integrated analysis, Climatic Change, 75, 273-299, 2006.

Li, F., Kustas, W. P., Anderson, M. C., Prueger, J. H., and Scott, R. L.: Effect of remote sensing spatial resolution on interpreting tower-based flux observations, Remote Sens. Environ., 112, 337349, 2008.

Mahrt, L., Vickers, D., and Sun, J.: Spatial variations of surface moisture flux from aircraft data, Adv. Water Resour., 24, 11331141, 2001.

Mallick, K., Bhattacharya, B. K., Chaurasia, S., Dutta, S., Nigam, R., Mukherjee, J., Banerjee, S., Kar, G., Rao, V. U. M., Gadgil, A. S., and Parihar J. S.: Evapotranspiration using MODIS data and limited ground observations over selected agroecosystems in India, Int. J. Remote Sens., 28, 2091-2110, 2007.

Mallick, K., Bhattacharya, B. K., Rao, V. U. M., Reddy, D. R., Banerjee, S., Hoshali, V., Pandey, V., Kar, G., Mukherjee, J., Vyas, S. P., Gadgil, A. S., and Patel, N. K.: Latent heat flux estimation in clear sky days over Indian agroecosystems using noontime satellite remote sensing data, Agr. Forest Meteorol., 149, 1646-1665, 2009.

Mallick, K., Jarvis, A., Wohlfahrt, G., Kiely, G., Hirano, T., Miyata, A., Yamamoto, S., and Hoffmann, L.: Components of near-surface energy balance derived from satellite soundings - Part 1: Net available energy, Biogeosciences Discuss., 11, 11825-11861, doi:10.5194/bgd-11-11825-2014, 2014.

McCabe, M. F. and Wood, E. F.: Scale influences on the remote estimation of evapotranspiration using multiple satellite sensors, Remote Sens. Environ., 105, 271-285, 2006.

McCabe, M. F., Wood, E. F., Wójcik, R., Pan, M., Sheffield, J., Gao, $\mathrm{H}$., and $\mathrm{Su}, \mathrm{H}$.: Hydrological consistency using multi-sensor remote sensing data for water and energy cycle studies, Remote Sens. Environ., 112, 430-444, 2008.

Mecikalksi, J. R., Diak, G. R., Anderson, M. C., and Norman, J. M.: Estimating fluxes on continental scales using remotely-sensed data in an atmospheric-land exchange model, J. Appl. Meteorol., 35, 1352-1369, 1999.

Miglietta, F., Gioli, B., Brunet, Y., Hutjes, R. W. A., Matese, A., Sarrat, C., and Zaldei, A.: Sensible and latent heat flux from radiometric surface temperatures at the regional scale: methodology and evaluation, Biogeosciences, 6, 1975-1986, doi:10.5194/bg6-1975-2009, 2009.

Mu, Q., Heinsch, F. A., Zhao, M., and Running, S. W.: Development of a global evapotranspiration algorithm based on MODIS and global meteorology data, Remote Sens. Environ., 111, 519-536, 2007.

Mu, Q., Zhao, M., and Running, S. W.: Improvements to a MODIS Global Terrestrial Evapotranspiration Algorithm, Remote Sens. Environ., 115, 1781-1800, 2011. 
Nickel, D., Barthel, R., and Braun, J.: Large-scale water resources management within the framework of GLOWA-Danube - The water supply model, Phys. Chem. Earth, 30, 383-388, 2005.

Norman, J. M., Kustas, W. P., and Humes, K. S.: A two-source approach for estimating soil and vegetation energy fluxes in observations of directional radiometric surface temperature, Agr. Forest Meteorol., 77, 263-293, 1995.

Nykanen, D. K. and Georgiou, E. F.: Soil moisture variability and scale-dependency of nonlinear parameterizations in coupled land-atmosphere models, Adv. Water. Res., 24, 1143-1157, 2001.

Perez, P. J., Castellvi, F., Ibanez, M., and Rosell, J. I.: Assessment of reliability of Bowen ratio method for partitioning fluxes, Agr. Forest Meteorol., 97, 141-150, 1999.

Priestley, C. B. H. and Taylor, R. J.: On the assessment of surface heat flux and evaporation using large scale parameters, Mon. Weather Rev., 100, 81-92, 1972.

Prueger, J. H., Hatfield, J. L., Kustas, W. P., Hipps, L. E., Macpherson, J. I., Neale, C. M. U., Eichinger, W. E., Cooper, D. I., and Parkin, T. B.: Tower and aircraft eddy covariance measurements of water vapor, energy, and carbon dioxide fluxes during SMACEX, J. Hydrometeorol., 6, 954-960, 2005.

Rider, N. E. and Philip, J. R.: Advection and evaporation, Association International of Hydrological Science, 53, 421-427, 1960.

Russell, J. M. and Johnson, T. C.: The water balance and stable isotope hydrology of Lake Edward, Uganda-Congo, J. Great Lakes Res., 32, 77-90, 2006.

Sahoo, A. K., Pan, M., Troy, T. J., Vinukollu, R. K., Sheffield, J., and Wood, E. F.: Reconciling the global terrestrial water budget using satellite remote sensing, Remote Sens. Environ., 115, 1850-1865, 2011.

Salby, M. L.: Fundamental of atmospheric physics, Academic Press, London, 1996.

Salvucci, G. D. and Gentine, P.: Emergent relation between surface vapor conductance and relative humidity profiles yields evaporation from weather data, P. Natl. Acad. Sci. USA, 110, 62876291, doi:10.1073/pnas.1215844110, 2013.

Shuttleworth, W. J., Gurney, R. J., Hsu, A. Y., and Ormsby, J. P.: FIFE: the variation in energy partition at surface flux sites, in: Remote Sensing and Large-Scale Processes, edited by: Rango, A., Proceedings of the IAHS third International Assembly, Baltimore, MD, May, IAHS Publication, 186, 67-74, 1989

Stisen, S., Sandholt, I., Nørgaard, A., Fensholt, R., and Jensen, K. H.: Combining the triangle method with thermal inertia to estimate regional evapotranspiration applied to MSG-SEVIRI data in the Senegal river basin, Remote Sens. Environ., 112, 1242 1255, 2008.

Stoy, P. C., Mauder, M., Foken, T., Marcolla, B., Boegh, E., Ibrom, A., Arain, M. A., Arneth, A., Aurela, M., Bernhofer, C., Cescatti, A., Dellwik, E., Duce, P., Gianelle, D., van Gorsel, E., Kiely, G., Knohl, A., Margolis, H., McCaughey, H., Merbold, L., Montagnani, L., Papale, D., Reichstein, M., Saunders, M., Serrano-Ortiz, P., Sottocornola, M., Spano, D., Vaccari, F., and Varlagin, A.: A data-driven analysis of energy balance closure across FLUXNET research sites: The role of landscape scale heterogeneity, Agr. Forest Meteorol., 171-172, 137-152, doi:10.1016/j.agrformet.2012.11.004, 2013.

Stull, R. B.: An Introduction to Boundary Layer Meteorology, Kluwer Academic Publishers, Dordrecht, 1988.
Swinbank, W. C. and Dyer, A. J.: An experimental study in micrometeorology, Q. J. Roy. Meteor. Soc., 93, 494-500, 1967.

Su, Z.: The Surface Energy Balance System (SEBS) for estimation of turbulent heat fluxes, Hydrol. Earth Syst. Sci., 6, 85-100, doi:10.5194/hess-6-85-2002, 2002.

Tanner, C. B.: A simple aero-heat budget method for determining daily evapotranspiration, Trans. Int. Congr. Soil Sci., 1, 203-209, 1961.

Tasumi, M., Allen, R. G., Trezza, R., and Wright, J. L.: Satellitebased energy balance to assess within-population variance of crop coefficient curves, J. Irrig. Drain. E.-ASCE, 131, 94-109, 2005.

Thompson, O. E., and Hou, W. T.: Coupling of horizontal, vertical , and temporal resolving power of a satellite temperature sounder, J. Atmos. Ocean. Tech., 7, 454-463, 1990.

Tobin, D. C., Revercomb, H. E., Knuteson, R. O., Lesht, B. M., Strow, L. L., Hannon, S. E., Feltz, W. F., Moy, L. A., Fetzer, E. J., and Cress, T. S.: Atmospheric Radiation Measurement site atmospheric state best estimates for Atmospheric Infrared Sounder temperature and water vapor retrieval validation, J. Geophys. Res., 111, D09S14, doi:10.1029/2005JD006103, 2006.

Todd, R., Evett, S. R., and Howell, T. A.: The Bowen ratio-energy balance method for estimating latent heat flux of irrigated alfalfa evaluated in a semi-arid, advective environment, Agr. Forest Meteorol., 103, 335-348, 2000.

Torralba, P. C., de Arellano, J. V. G., Bosveld, F., Soler, M. R., Vermeulen, A., Werner, C., and Moors, E.: Diurnal and vertical variability of the sensible heat and carbon dioxide budgets in the atmospheric surface layer, J. Geophys. Res., 113, D12119, doi:10.1029/2007JD009583, 2008.

Verma, S. B., Rosenberg, N. J., and Blad, B. L.: Turbulent exchange coefficients for sensible heat and water vapor under advective conditions, J. Appl. Meteorol., 17, 330-338, 1978.

Verstraeten, W. W., Veroustraete, F., and Feyen, J.: Estimating evapotranspiration of European forests from NOAA-imagery at satellite overpass time: towards an operational processing chain for integrated optical and thermal sensor data products, Remote Sens. Environ., 96, 256-276, 2005.

Vinukollu, R. K., Wood, E. F., Ferguson, C. R., and Fisher, J. B.: Global estimates of evapotranspiration for climate studies using multi-sensor remote sensing data: Evaluation of three processbased approaches, Remote Sens. Environ., 115, 801-823, 2011.

Wilson, J. D., Flesch, T. K., and Harper, L. A.: Micrometeorological methods for estimating surface exchange with a disturbed windflow, Agr. Forest Meteorol., 107, 207-225, 2001.

Wilson, K. B., Goldstein, A. H., Falge, E., Aubinet, M., Baldocchi, D., Berbigier, P., Bernhofer, Ch., Ceulemans, R., Dolman, H., Field, C., Grelle, A., Law, B., Meyers, T., Moncrieff, J., Monson, R., Oechel, W., Tenhunen, J., Valentini, R., and Verma, S.: Energy balance closure at FLUXNET sites, Agr. Forest Meteorol., 113, 223-243, 2002.

Wohlfahrt, G., Haslwanter, A., Hörtnagl, L., Jasoni, R. L., Fenstermaker, L. F., Arnone III, J. A., and Hammerle, A.: On the consequences of the energy imbalance for calculating surface conductance to water vapor, Agr. Forest Meteorol., 149, 1556-1559, 2009. 